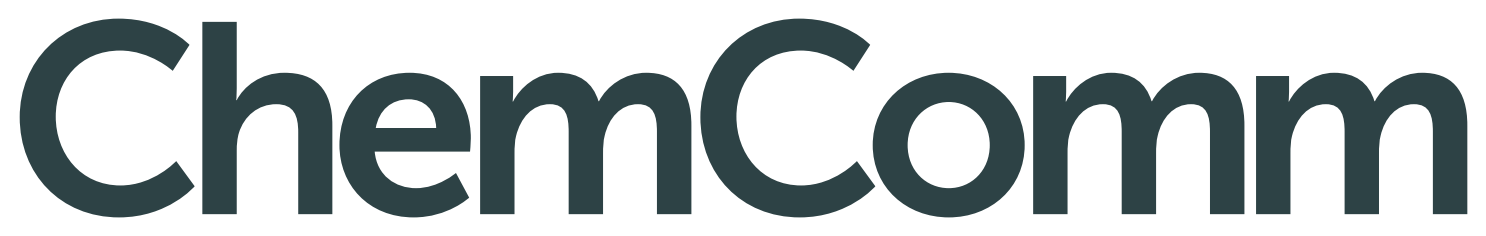

Chemical Communications

www.rsc.org/chemcomm

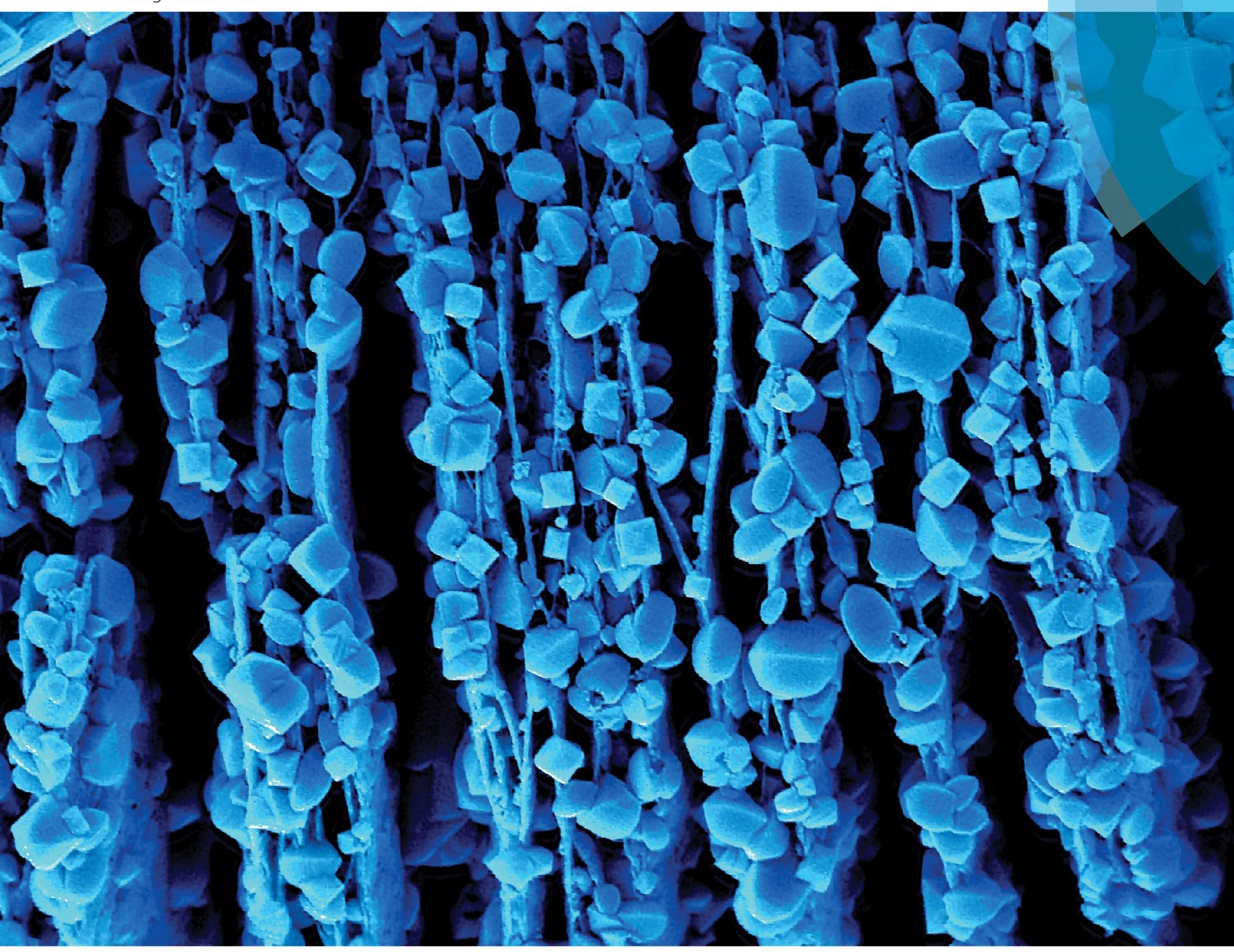

ISSN 1359-7345

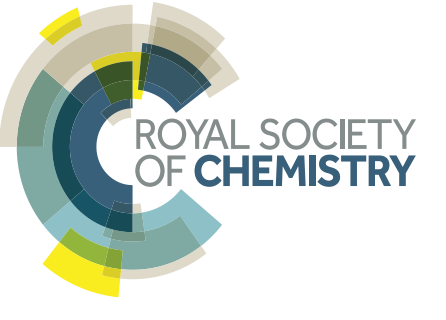




\section{One-step synthesis of nanocrystalline transition metal oxides on thin sheets of disordered graphitic carbon by oxidation of MXenes $\dagger$}

Cite this: Chem. Commun., 2014, 50,7420

Received 4th March 2014, Accepted 15th April 2014

DOI: $10.1039 / c 4 c c 01646 g$

www.rsc.org/chemcomm

\author{
Michael Naguib, ${ }^{a b}$ Olha Mashtalir, ${ }^{a b}$ Maria R. Lukatskaya, ${ }^{a b}$ Boris Dyatkin, ${ }^{a b}$ \\ Chuanfang Zhang, ${ }^{\text {ab }}$ Volker Presser, ${ }^{c}$ Yury Gogotsi ${ }^{\mathrm{ab}}$ and Michel W. Barsoum ${ }^{\star a}$
}

\begin{abstract}
Herein we show that heating $2 \mathrm{D} \mathrm{Ti}_{3} \mathrm{C}_{2}$ in air results in $\mathrm{TiO}_{2}$ nanocrystals enmeshed in thin sheets of disordered graphitic carbon structures that can handle extremely high cycling rates when tested as anodes in lithium ion batteries. Oxidation of $2 \mathrm{D} \mathrm{Ti}_{3} \mathrm{C}_{2}$ in either $\mathrm{CO}_{2}$ or pressurized water also resulted in $\mathrm{TiO}_{2}-\mathrm{C}$ hybrid structures. Similarly, other hybrids can be produced, as we show here for $\mathrm{Nb}_{2} \mathrm{O}_{5} / \mathrm{C}$ from 2D Nb${ }_{2} \mathrm{C}$.
\end{abstract}

Among the myriad metal oxide/carbon materials, titania-carbon hybrids $\left(\mathrm{TiO}_{2}-\mathrm{C}\right)$ have attracted the most attention due to their superior performance in many applications. For example, nanocrystalline titania deposited on graphene is an excellent photocatalyst $^{1-4}$ and an outstanding electrode material in lithium-ion batteries (LIBs). ${ }^{5-8}$ To date, most of the synthesis techniques have been carried out using at least two main steps: graphene synthesis, followed by deposition of $\mathrm{TiO}_{2}$, with each step possibly consisting of multiple intermediate stages (e.g., solution deposition of amorphous $\mathrm{TiO}_{2}$ followed by calcination to crystallize the oxide structure). ${ }^{8}$ In addition, an advanced one-step synthesis of a $\mathrm{TiO}_{2}$-graphene hybrid was achieved by solvothermal treatment of graphene oxide mixed with titania precursor solutions. ${ }^{9-12}$

Recently, we reported on the synthesis of a new family of two-dimensional (2D) transition metal carbides and carbonitrides, that we labeled MXenes. ${ }^{13-15}$ The latter have a composition of $\mathrm{M}_{n+1} \mathrm{X}_{n}$, where $\mathrm{M}$ stands for an early transition metal, $\mathrm{X}$ stands for carbon or nitrogen and $n=1,2$, or $3 .{ }^{16}$ To date the following have been reported: $\mathrm{Ti}_{2} \mathrm{C}, \mathrm{V}_{2} \mathrm{C}, \mathrm{Nb}_{2} \mathrm{C},\left(\mathrm{Ti}_{0.5}, \mathrm{Nb}_{0.5}\right)_{2} \mathrm{C}$,

\footnotetext{
${ }^{a}$ Department of Materials Science \& Engineering, Drexel University, Philadelphia, PA 19104, USA. E-mail: barsoumw@drexel.edu; Fax: +1 215895 6760; Tel: +12158952338

${ }^{b}$ A. J. Drexel Nanomaterials Institute, Drexel University, Philadelphia, PA 19104, USA. E-mail: gogotsi@drexel.edu; Fax: +1 215895 1934; Tel: +1 2158956446 ${ }^{c}$ INM - Leibniz Institute for New Materials \& Saarland University, 66123 Saarbrücken, Germany. E-mail: volker.presser@inm-gmbh.de; Tel: +496819300177

$\dagger$ Electronic supplementary information (ESI) available: Experimental details for; LIBs preparation and testing procedures, the delamination procedure using XRD and SEM after oxidation, $\mathrm{CO}_{2}$ and hydrothermal oxidation using SEM, XRD, and Raman spectroscopy. See DOI: 10.1039/c4cc01646g
}

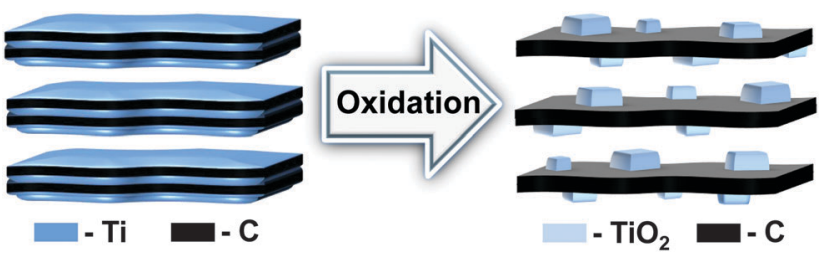

Fig. 1 Schematic of MXene oxidation and formation of oxide-graphitic disordered carbon hybrid structure.

$\mathrm{Ti}_{3} \mathrm{C}_{2}, \mathrm{Ti}_{3} \mathrm{CN},\left(\mathrm{V}_{0.5}, \mathrm{Cr}_{0.5}\right)_{3} \mathrm{C}_{2}$, and $\mathrm{Ta}_{4} \mathrm{C}_{3},{ }^{13-15}$ with $\mathrm{Ti}_{3} \mathrm{C}_{2}$ being the most investigated one. ${ }^{14}$

Herein, we report on the one-step synthesis of thin sheets of disordered graphitic carbon, decorated with oxide nanocrystals (Fig. 1) of anatase or niobia, $\mathrm{Nb}_{2} \mathrm{O}_{5}$, by oxidizing $2 \mathrm{D} \mathrm{Ti}_{3} \mathrm{C}_{2}$ or $\mathrm{Nb}_{2} \mathrm{C}$ powders, respectively. In the $\mathrm{Ti}_{3} \mathrm{C}_{2}$ case, powders were flash oxidized in air at $1150{ }^{\circ} \mathrm{C}$ for $30 \mathrm{~s}$. The resulting hybrid structure showed good performance as an anode material in LIBs at high rates. Similar structures were obtained by oxidizing $\mathrm{Ti}_{3} \mathrm{C}_{2}$ in $\mathrm{CO}_{2}$ between 150 and $300{ }^{\circ} \mathrm{C}$, or by a hydrothermal treatment in an autoclave at $150-250{ }^{\circ} \mathrm{C}$ in the 1-5 MPa pressure range.

The synthesis of the $\mathrm{Ti}_{3} \mathrm{C}_{2}$ powders is described in detail elsewhere. ${ }^{14}$ In brief, the $\mathrm{Ti}_{3} \mathrm{C}_{2}$-based MXene powders were produced by etching $\mathrm{Al}$ from $\mathrm{Ti}_{3} \mathrm{AlC}_{2}$ powders in aqueous $\mathrm{HF}$ (50\% conc.) solutions at room temperature, RT. ${ }^{14}$ The as-synthesized $\mathrm{Ti}_{3} \mathrm{C}_{2}$ surfaces are terminated by a combination of $-\mathrm{OH},=\mathrm{O}$, and/or -F groups. ${ }^{14}$ For simplicity, we will use " $\mathrm{Ti}_{3} \mathrm{C}_{2} \mathrm{~T}_{x}$ " to represent the as-synthesized surface terminated MXenes, where $\mathrm{T}_{x}$ stands for terminational functional groups. Free-standing paper was also fabricated by filtration of a colloidal solution of delaminated flakes of $\mathrm{Ti}_{3} \mathrm{C}_{2} \mathrm{~T}_{x}$ (referred to as $\mathrm{d}-\mathrm{Ti}_{3} \mathrm{C}_{2} \mathrm{~T}_{x}$ ) in water. The details of the delamination process are summarized in the ESI $\dagger$ and ref. 17.

MXene powders or paper were placed in alumina boats, and flash oxidized at $1150{ }^{\circ} \mathrm{C}$ by rapidly ( $<5 \mathrm{~s}$ ) pushing the boat into the furnace's hot zone where the boat was kept at $1150{ }^{\circ} \mathrm{C}$ for $30 \mathrm{~s}$, before being rapidly removed from the furnace in $<5 \mathrm{~s}$. One of the challenges of flash oxidation is the difficulty in controlling the process, especially if ignition of the powders takes place. To explore 

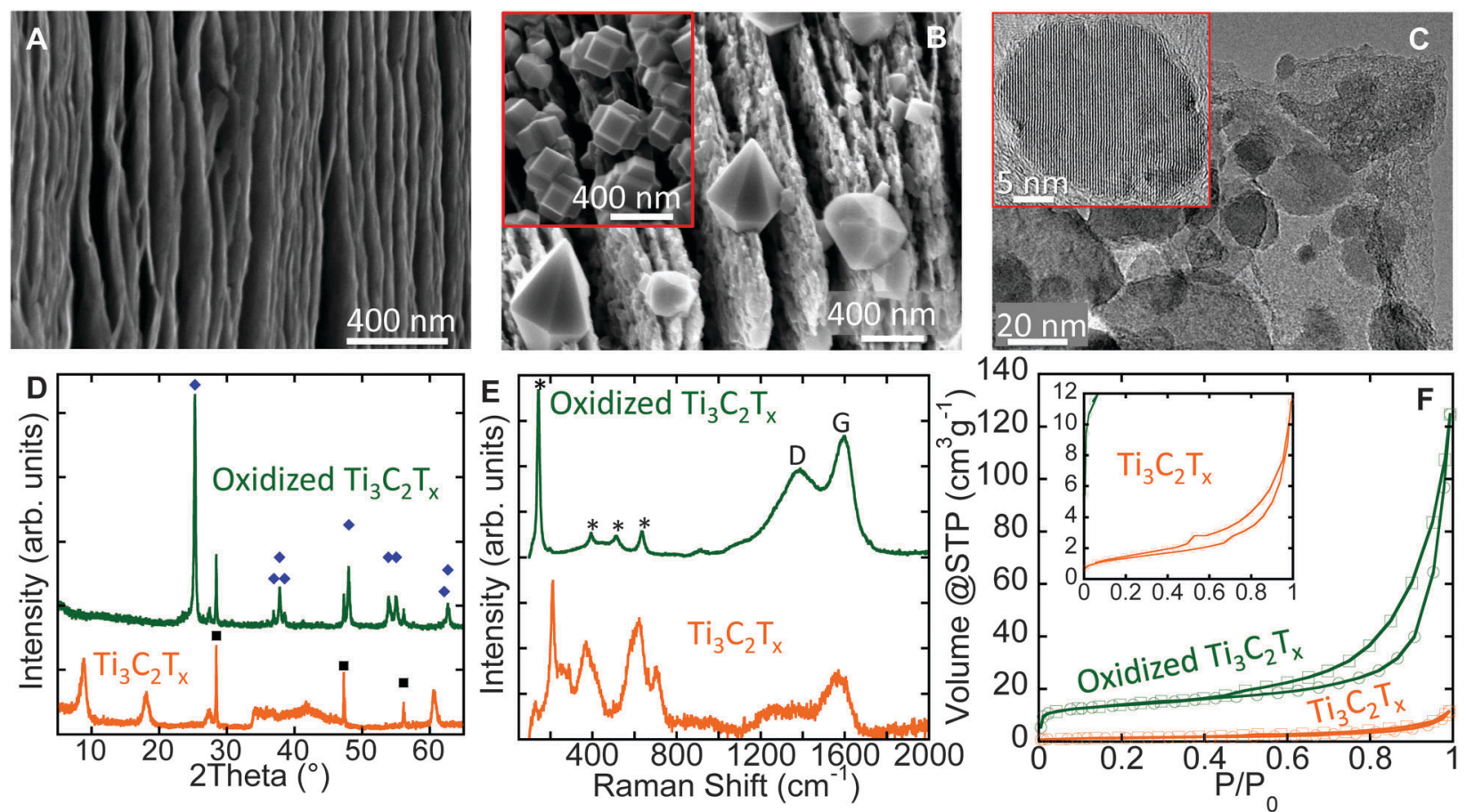

Fig. 2 Characterization of $\mathrm{Ti}_{3} \mathrm{C}_{2} \mathrm{~T}_{x}$ powders before and after flash oxidation in air at $1150{ }^{\circ} \mathrm{C}$ for $30 \mathrm{~s}$. (A) SEM image of typical as-synthesized multilayers $\mathrm{Ti}_{3} \mathrm{C}_{2} \mathrm{~T}_{x}$. (B) SEM image after oxidation. Top left inset is another SEM image at a different location for the same sample. (C) TEM image after oxidation. Inset is a high-magnification image of one of the anatase particles embedded in the amorphous carbon. (D) XRD patterns before and after oxidation. The blue diamonds denote anatase peak positions for (PDF\#01-0562); squares denote Si peak positions which was used as an internal reference. (E) Raman spectra before and after oxidation; the stars represent anatase; $D$ and $G$ represent the positions of $D$ and $G$ bands of disordered graphitic carbon. (F) Nitrogen adsorption-desorption isotherms at $-196{ }^{\circ} \mathrm{C}$ for $\mathrm{Ti}_{3} \mathrm{C}_{2} \mathrm{~T}_{x}$ before and after oxidation. The inset shows a zoom of the $\mathrm{Ti}_{3} \mathrm{C}_{2} \mathrm{~T}_{x}$ isotherms along the $Y$-axis.

more controlled approaches MXene powders were: (i) held for $1 \mathrm{~h}$ in pure $\mathrm{CO}_{2}$ at 150,300 , and $500{ }^{\circ} \mathrm{C}$ and, (ii) heated hydrothermally in deionized (DI) water at 150,200 , and $250{ }^{\circ} \mathrm{C}$ for $48 \mathrm{~h}, 8-20 \mathrm{~h}$ and $2 \mathrm{~h}$, respectively, in an autoclave. Further details can be found in the ESI. $\dagger$

The as-synthesized $\mathrm{Ti}_{3} \mathrm{C}_{2} \mathrm{~T}_{x}$ has a layered morphology resembling exfoliated graphite (Fig. 2A). ${ }^{18}$ After flash oxidation, oxide nanocrystals were observed to grow between, and at the edges of the layers (Fig. 2B). Energy dispersive X-ray analysis (EDX) showed them to be comprised of Ti and O. Several relatively large $(<0.5 \mu \mathrm{m})$ bi-pyramidal $\mathrm{TiO}_{2}$ crystals (Fig. 2B) were observed as well, and their morphology suggests they are anatase. Similar nanometer-sized anatase bi-pyramids, with $\{101\}$-plane faceting were reported by Čaplovičová et al. ${ }^{19}$ for $\mathrm{TiO}_{2}$ derived from conventional mechanochemical synthesis and found to be highly photoactive. Note that nanocuboids were also observed in some scanning electron microscope (SEM) images (inset, Fig. 2B).

The cuboids are likely to consist of $\{001\}$ and $\{100\}$ facets. ${ }^{20}$ The presence of the latter is not surprising, since the starting $\mathrm{Ti}_{3} \mathrm{C}_{2} \mathrm{~T}_{x}$ contained a significant fraction of $-\mathrm{F}$ surface terminations which are known to stabilize the $\{001\}$ anatase surfaces. ${ }^{21}$ Sun et al. ${ }^{22}$ showed a significant improvement in photocatalytic activity under visible light for composites of anatase nanocrystals with exposed $\{001\}$-facets on graphene sheets, as compared to pure $\mathrm{TiO}_{2}$ nanosheets. The existence of these various morphologies demonstrates that MXenes can be used as facile precursors to create tailored morphologies. Further experiments, however, are needed to tune the oxidation process to solely obtain a specific morphology.

Transmission electron microscope (TEM) images of oxidized $\mathrm{Ti}_{3} \mathrm{C}_{2} \mathrm{~T}_{x}$ (Fig. 2C) show that the nanocrystals are embedded in thin sheets. EDX of the sheets showed mainly $\mathrm{C}$ with some Ti, and $\mathrm{O}$. The $d$-spacing between the atomic planes in the nanocrystals was measured from lattice fringes in TEM images (inset, Fig. 2C), and matched the (101) $d$-spacing of anatase, viz. 3.5 A. The conversion of $\mathrm{Ti}_{3} \mathrm{C}_{2} \mathrm{~T}_{x}$ into nanocrystalline anatase and amorphous $\mathrm{C}$ was confirmed by X-ray diffraction (XRD) and Raman spectroscopy and the results are shown in Fig. 2D and E, respectively. The average anatase domain size, estimated from the XRD patterns is $\sim 60 \mathrm{~nm}$ using the Scherrer formula. ${ }^{23}$

The Raman spectrum of oxidized $\mathrm{Ti}_{3} \mathrm{C}_{2} \mathrm{~T}_{x}$ powders (top spectrum in Fig. 2E) showed a strong peak at $144 \mathrm{~cm}^{-1}$ with a full width of half maximum (FWHM) of $14 \mathrm{~cm}^{-1}$, together with three other peaks at 394,513 , and $635 \mathrm{~cm}^{-1}$. These peaks can be assigned to the following anatase vibrational modes: $\mathrm{E}_{\mathrm{g}(1)}, \mathrm{B}_{1 \mathrm{~g}(1)}, \mathrm{A}_{1 \mathrm{~g}} \& \mathrm{~B}_{1 \mathrm{~g}(2)}$, and $\mathrm{E}_{\mathrm{g}(3)}$, respectively. ${ }^{24}$ The peak positions and FWHM of $\mathrm{E}_{\mathrm{g}(1)}$ correspond to anatase particles with an average size of less than $15 \mathrm{~nm}^{24}$ The discrepancy between the average sizes obtained from XRD patterns and Raman spectra relates to the nature of each technique. In XRD, the average domain size obtained is averaged over a larger sampling volume; the values obtained from Raman spectra are more strongly affected by crystal lattice defects within the grains that lead to smaller scattering domains. ${ }^{25}$ The two broad peaks between 1000 and $1800 \mathrm{~cm}^{-1}$ are characteristic for the D- and 
G-modes of graphitic carbon. ${ }^{26}$ The D-band position and its FWHM were $1391 \mathrm{~cm}^{-1}$ and $225 \mathrm{~cm}^{-1}$, respectively. The corresponding values of the G-band were $1596 \mathrm{~cm}^{-1}$ and $91 \mathrm{~cm}^{-1}$. The ratio of the $\mathrm{D}$ - and G-band intensities, $I_{\mathrm{D}} / I_{\mathrm{G}}$, was $\sim 0.78$. The broadening of G- and D- bands and the $I_{\mathrm{D}} / I_{\mathrm{G}}$ ratio evidence highly disordered (amorphous) carbon similar to what has been reported for carbide-derived carbons (CDCs) fabricated at $200{ }^{\circ} \mathrm{C} .{ }^{27}$ The presence of carbon sheets covered by $\mathrm{TiO}_{2}$ particles on the surface implies that the innermost Ti atoms in the MXene structure migrated outward to react with oxygen. This outward migration of $\mathrm{Ti}$ is similar to what has been observed previously during the oxidation of TiN. ${ }^{28}$

The $\mathrm{N}_{2}$ adsorption-desorption isotherms at $-196{ }^{\circ} \mathrm{C}$ (Fig. $2 \mathrm{~F}$ ) show an increase in the specific surface area (SSA) after oxidation. The SSA estimated using the BET equation ${ }^{29}$ for the oxidized sample was found to be $\sim 50 \mathrm{~m}^{2} \mathrm{~g}^{-1}$, a factor of 5 greater than that of the as-synthesized MXene, which had a SSA of $10 \mathrm{~m}^{2} \mathrm{~g}^{-1}$. This increase in SSA could be explained by the: (i) formation of nanometer-sized oxide particles and/or, (ii) opening or swelling of the layers during oxidation that allows the adsorbate to penetrate between the layers.

Flash oxidation of $2-4 \mu \mathrm{m}$ thick $\mathrm{d}-\mathrm{Ti}_{3} \mathrm{C}_{2} \mathrm{~T}_{x}$ "paper" in air at $1150{ }^{\circ} \mathrm{C}$ for $30 \mathrm{~s}$ changed it from opaque black to translucent white. Interestingly, unlike the $\mathrm{Ti}_{3} \mathrm{C}_{2} \mathrm{~T}_{x}$ powders, oxidation of the paper did not result in the formation of crystalline phases detectable by XRD (Fig. S1A and S1B, ESI $\dagger$ ). This can be explained by an easier oxygen access to each single or a fewlayer-flakes of the MXene paper, resulting in more uniform oxidation and the formation of extremely thin and uniform $\mathrm{TiO}_{2}$ particles. For multilayered stacked $\mathrm{Ti}_{3} \mathrm{C}_{2} \mathrm{~T}_{x}$ powders, a gradient of oxygen concentration (high outside the particle and lower inside) is expected. This in turn, results in formation of relatively large $\mathrm{TiO}_{2}$ crystals (Fig. 2B) on the surface, similar to oxidation of the $\mathrm{Si}_{3} \mathrm{~N}_{4}$-TiN composite. ${ }^{28}$

The characterization results for the isothermal oxidation of $\mathrm{Ti}_{3} \mathrm{C}_{2} \mathrm{~T}_{x}$ in $\mathrm{CO}_{2}$ and hydrothermal oxidation in DI water are presented and discussed in detail in the ESI. $\dagger$ As shown in Fig. S2A (ESI $\dagger$ ), anatase formation was observed by XRD when $\mathrm{CO}_{2}$ was used at $150{ }^{\circ} \mathrm{C}$ and higher temperatures. Note that the XRD patterns show the presence of some unreacted MXene along with the anatase after oxidation in $\mathrm{CO}_{2}$ at $500{ }^{\circ} \mathrm{C}$. The presence of disordered carbon was confirmed using Raman spectroscopy (Fig. S2C, ESI $\dagger$ ). The morphology of the material oxidized using $\mathrm{CO}_{2}$ (Fig. S2B, ESI $\dagger$ ) is similar to what was observed after flash oxidation in air at $1150{ }^{\circ} \mathrm{C}$. In the samples that were oxidized in $\mathrm{CO}_{2}$ no bi-pyramidal crystals were observed.

The XRD patterns (Fig. S3, ESI $\dagger$ ) after hydrothermal treatment in DI water also show incomplete oxidation and the co-existence of $\mathrm{Ti}_{3} \mathrm{C}_{2} \mathrm{~T}_{x}$ and anatase peaks. As shown in Fig. S4 (ESI $\dagger$ ), the most uniform oxide morphology was obtained using this technique. No bare MXene sheets (similar to Fig. 2A) were observed by SEM (Fig. S4, ESI $\dagger$ ), which could be due to the presence of unreacted MXene in the core and oxide particles on the surface (core-shell morphology).

To investigate the performance of the hybrid structures produced herein, we tested one of the samples that was produced
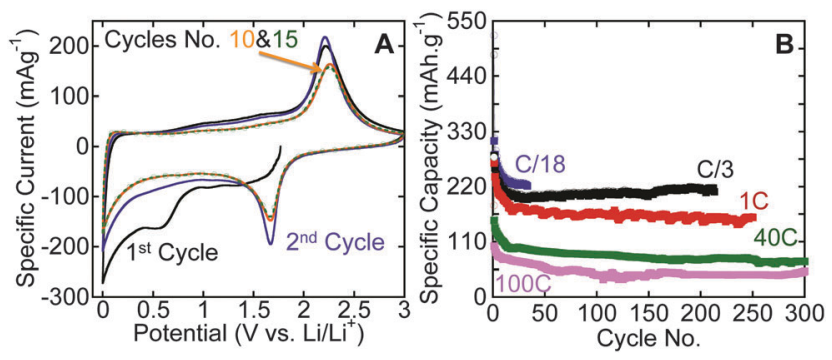

Fig. 3 Electrochemical performance of flash-oxidized $\mathrm{Ti}_{3} \mathrm{C}_{2} \mathrm{~T}_{x}$ powders in LIBs (A) CVs at a rate of $0.2 \mathrm{mV} \mathrm{s}^{-1}$; (B) effect of cycling on Li capacity at various rates.

by flash oxidation in air, as an electrode material in LIBs. Fig. 3A shows cyclic voltammograms (CVs) for flash-air oxidized $\mathrm{Ti}_{3} \mathrm{C}_{2} \mathrm{~T}_{x}$ powders. The reversible lithiation and delithiation peaks, respectively, at around 1.7 and $2.2 \mathrm{~V} v s . \mathrm{Li}^{\prime} \mathrm{Li}^{+}$are quite close to what was reported for nanocrystalline anatase anodes. ${ }^{30,31}$ Similar peaks were observed for hydrothermally treated $\mathrm{Ti}_{3} \mathrm{C}_{2} \mathrm{~T}_{x}$ (Fig. S5, ESI $\dagger$ ). As shown in Fig. 3B, reversible capacities of $220 \mathrm{~mA} \mathrm{~h} \mathrm{~g}^{-1}$ after 30 cycles at a cycling rate of $\mathrm{C} / 18,210 \mathrm{~mA} \mathrm{~h} \mathrm{~g}^{-1}$ after more than 200 cycles at $\mathrm{C} / 3$, and $155 \mathrm{~mA} \mathrm{~h} \mathrm{~g}^{-1}$ after 250 cycles at $1 \mathrm{C}$ were obtained. These capacities are higher than those reported for anatase powder electrodes and comparable to those reported for anatase-functionalized hybrid structures of graphene sheets. ${ }^{8}$ Cai et al. $^{32}$ reported a capacity of about $300 \mathrm{~mA} \mathrm{~h} \mathrm{~g}{ }^{-1}$ at $1 \mathrm{C}$ for $\mathrm{TiO}_{2}$-graphene composites within the same voltage window used here. The higher capacity they reported can be explained by the amount of graphene used in their composites which was more than double the carbon content in this work. It is worth noting that the maximum amount of carbon in our work after oxidation - assuming that no carbon is oxidized - is about $10 \mathrm{wt} \%$. Said otherwise, if none of the carbon is oxidized and all the Ti is converted into $\mathrm{TiO}_{2}$, then the $\mathrm{C}: \mathrm{TiO}_{2}$ ratio by mass should be $\sim 1: 10$.

When we tested our material at very high rates, viz. $40 \mathrm{C}$ and $100 \mathrm{C}$, reversible capacities of $75 \mathrm{~mA} \mathrm{~h} \mathrm{~g}^{-1}$ and $45 \mathrm{~mA} \mathrm{~h} \mathrm{~g}^{-1}$, respectively, were obtained after more than 250 cycles. These high cycling rates cannot be achieved with graphite electrodes and are better than what was reported for anatase. For example, Shin et al. ${ }^{33}$ found that 5 to $10 \mathrm{~nm}$ anatase had no capacity at cycling rates of $30 \mathrm{C}$ and $60 \mathrm{C}$, while nanoporous anatase had capacities of $77 \mathrm{~mA} \mathrm{~h} \mathrm{~g}^{-1}$ and $46 \mathrm{~mA} \mathrm{~h} \mathrm{~g}^{-1}$ at $30 \mathrm{C}$ and $60 \mathrm{C}$, respectively. In that paper it was suggested that the good capacity at high cycling rates was due to interfacial storage. ${ }^{33}$

As noted above, $\mathrm{Ti}_{3} \mathrm{C}_{2} \mathrm{~T}_{x}$ is just one member of the much larger MXene family. It follows that this work opens the door to numerous hybrid structures, of different nanocrystalline early transition metal oxides, on disordered graphitic carbon thin sheets. To prove the generality of the proposed approach, another MXene, viz. $\mathrm{Nb}_{2} \mathrm{CT}_{x}{ }^{15}$ was oxidized by hydrothermal treatment in DI water at $150{ }^{\circ} \mathrm{C}$ for $4 \mathrm{~h}$ and at $200{ }^{\circ} \mathrm{C}$ for $2 \mathrm{~h}$. The experimental details are similar to those described in the ESI $\dagger$ for $\mathrm{Ti}_{3} \mathrm{C}_{2} \mathrm{~T}_{x}$. As shown in Fig. S6A (ESI $\dagger$ ), this procedure produced $\mathrm{Nb}_{2} \mathrm{O}_{5}$ after $4 \mathrm{~h}$ at $200{ }^{\circ} \mathrm{C}$. Interestingly, no peaks related to crystalline oxides were observed in the XRD patterns after 
treatment at $150{ }^{\circ} \mathrm{C}$ for $2 \mathrm{~h}$. A broad Raman peak of $\mathrm{Nb}_{2} \mathrm{O}_{5}$ at around $700 \mathrm{~cm}^{-1}$ (Fig. S6B, ESI $\dagger$ ), similar to what was reported by Ghosh et al. ${ }^{34}$ for $\mathrm{Nb}_{2} \mathrm{O}_{5}$ nanoforests, was observed in both cases. The co-existence of amorphous carbon and metal oxide can be seen in the Raman spectra after oxidation at $200{ }^{\circ} \mathrm{C}$. In some locations, both carbon and niobia peaks were observed (Fig. S6B, ESI $\dagger$ ), in others the carbon peak was not observed (dotted black spectrum in Fig. S6B, ESI $\dagger$ ), which indicates that $200{ }^{\circ} \mathrm{C}$ may be too high if both oxide and carbon are desired. Further work is ongoing to fully convert $\mathrm{Nb}_{2} \mathrm{CT}_{x}$ into nanosized oxides without sacrificing the carbon. For example, reducing the molar ratio of $\mathrm{H}_{2} \mathrm{O}$ to MXene during hydrothermal treatment would yield a higher carbon content, similar to what was reported for binary transition metal carbides. ${ }^{35}$ Based on previous work, it is reasonable to conclude that the $\mathrm{Nb}_{2} \mathrm{O}_{5} / \mathrm{C}$ composites made herein could possibly be quite useful in electrochemical capacitors ${ }^{36}$ and LIBs. ${ }^{37}$

As shown in Fig. S6C (ESI $\dagger$ ), featherlike nano-particles were formed on the surfaces of the $\mathrm{Nb}_{2} \mathrm{CT}_{x}$ sheets after hydrothermal oxidation at $150{ }^{\circ} \mathrm{C}$. A few barrel-shaped oxide particles, with diameters of $\sim 200 \mathrm{~nm}$, were observed as well. Those barrelshaped oxide particles became the dominant morphology after the $200{ }^{\circ} \mathrm{C}$ treatment (Fig. S6D, ESI $\dagger$ ). It follows that the $150{ }^{\circ} \mathrm{C}$ treatment resulted in a hybrid structure of $\mathrm{Nb}_{2} \mathrm{CT}_{x}$, featherlike niobia and amorphous carbon. The $200{ }^{\circ} \mathrm{C}$ treatment resulted in mainly barrel-shaped nanocrystalline oxide particles and amorphous carbon, with a small amount of unreacted $\mathrm{Nb}_{2} \mathrm{CT}_{x}$.

In summary, flash oxidation of $2 \mathrm{D} \mathrm{Ti}_{3} \mathrm{C}_{2} \mathrm{~T}_{x}$ in air resulted in the formation of a hybrid structure of thin sheets of disordered graphitic carbon decorated with nanocrystalline anatase. The flash oxidized MXene powder showed higher capacities than nanoanatase in LIBs anodes at slow cycling rates (reversible capacities of $220 \mathrm{~mA} \mathrm{~h} \mathrm{~g}^{-1}$ and $210 \mathrm{~mA} \mathrm{~h} \mathrm{~g}^{-1}$ were obtained at C/18 and C/3, respectively), and an excellent capability to handle high cycling rates. At cycling rates of $1 \mathrm{C}, 40 \mathrm{C}$, and $100 \mathrm{C}$, reversible capacities of $155 \mathrm{~mA} \mathrm{~h} \mathrm{~g}^{-1}$ for 250 cycles $75 \mathrm{~mA} \mathrm{~h} \mathrm{~g}{ }^{-1}$ for 300 cycles, and $45 \mathrm{~mA} \mathrm{~h} \mathrm{~g}^{-1}$ for 300 cycles, respectively, were measured.

Oxidation in $\mathrm{CO}_{2}$ and hydrothermal oxidation of $\mathrm{Ti}_{3} \mathrm{C}_{2} \mathrm{~T}_{x}$ in DI water can also be used to produce hybrid structures of nanocrystalline anatase with amorphous $\mathrm{C}$, but at significantly lower temperatures. Formation of the most uniform oxide particles was achieved by hydrothermal oxidation. However, when $\mathrm{Ti}_{3} \mathrm{C}_{2} \mathrm{~T}_{x}$ powders were oxidized in $\mathrm{CO}_{2}$ or hydrothermally, the resulting powders contained unreacted $\mathrm{Ti}_{3} \mathrm{C}_{2} \mathrm{~T}_{x}$, anatase and C. Similarly, $\mathrm{Nb}_{2} \mathrm{O}_{5}$ with amorphous $\mathrm{C}$ and unreacted $\mathrm{Nb}_{2} \mathrm{CT}_{x}$ hybrid structures were obtained by hydrothermal treatment of the latter in DI water.

This work was supported by the National Science Foundation (DMR-1310245). MN is grateful to DAAD that partially supported him. Mr K.-P. Schmitt at INM is acknowledged for his help in carrying out the hydrothermal treatments. BD was supported by NSF (CNS0960061). VP thanks Prof. Eduard Arzt for his support and acknowledges funding from the German Federal Ministry for Research and Education in support of the nanoEES ${ }^{3 \mathrm{D}}$ project (03EK3013). CZ was supported by the Chinese Scholarship Council (CSC).

\section{Notes and references}

1 V. Štengl, D. Popelková and P. Vláčil, J. Phys. Chem. C, 2011, 115, $25209-25218$.

2 X.-Y. Zhang, H.-P. Li, X.-L. Cui and Y. Lin, J. Mater. Chem., 2010, 20, 2801-2806.

3 X. An and J. C. Yu, RSC Adv., 2011, 1, 1426-1434.

4 R. Leary and A. Westwood, Carbon, 2011, 49, 741-772.

5 J. Qiu, P. Zhang, M. Ling, S. Li, P. Liu, H. Zhao and S. Zhang, ACS Appl. Mater. Interfaces, 2012, 4, 3636-3642.

6 N. Li, G. Liu, C. Zhen, F. Li, L. Zhang and H.-M. Cheng, Adv. Funct. Mater., 2011, 21, 1717-1722.

7 X. Xin, X. Zhou, J. Wu, X. Yao and Z. Liu, ACS Nano, 2012, 6, 11035-11043.

8 D. Wang, D. Choi, J. Li, Z. Yang, Z. Nie, R. Kou, D. Hu, C. Wang, L. V. Saraf, J. Zhang, I. A. Aksay and J. Liu, ACS Nano, 2009, 3, 907-914.

9 J. Shen, B. Yan, M. Shi, H. Ma, N. Li and M. Ye, J. Mater. Chem., 2011, 21, 3415-3421.

10 J. S. Lee, K. H. You and C. B. Park, Adv. Mater., 2012, 24, 1084-1088.

11 K. Li, J. Xiong, T. Chen, L. Yan, Y. Dai, D. Song, Y. Lv and Z. Zeng, J. Hazard. Mater., 2013, 250-251, 19-28.

12 M. S. A. Sher Shah, A. R. Park, K. Zhang, J. H. Park and P. J. Yoo, ACS Appl. Mater. Interfaces, 2012, 4, 3893-3901.

13 M. Naguib, O. Mashtalir, J. Carle, V. Presser, J. Lu, L. Hultman, Y. Gogotsi and M. W. Barsoum, ACS Nano, 2012, 6, 1322-1331.

14 M. Naguib, M. Kurtoglu, V. Presser, J. Lu, J. Niu, M. Heon, L. Hultman, Y. Gogotsi and M. W. Barsoum, Adv. Mater., 2011, 23, 4248-4253.

15 M. Naguib, J. Halim, J. Lu, K. M. Cook, L. Hultman, Y. Gogotsi and M. W. Barsoum, J. Am. Chem. Soc., 2013, 135, 15966-15969.

16 M. Naguib, V. N. Mochalin, M. W. Barsoum and Y. Gogotsi, Adv. Mater., 2014, 26, 992-1005.

17 O. Mashtalir, M. Naguib, V. N. Mochalin, Y. Dall'Agnese, M. Heon, M. W. Barsoum and Y. Gogotsi, Nat. Commun., 2013, 4, 1716.

18 L. M. Viculis, J. J. Mack, O. M. Mayer, H. T. Hahn and R. B. Kaner, J. Mater. Chem., 2005, 15, 974-978.

19 M. Čaplovičová, P. Billik, Ľ. Čaplovič, V. Brezová, T. Turáni, G. Plesch and P. Fejdi, Appl. Catal., B, 2012, 117-118, 224-235.

20 L. Wang, L. Zang, J. Zhao and C. Wang, Chem. Commun., 2012, 48, 11736-11738.

21 W.-J. Ong, L.-L. Tan, S.-P. Chai, S.-T. Yong and A. R. Mohamed, Nanoscale, 2014, 6, 1946-2008.

22 L. Sun, Z. Zhao, Y. Zhou and L. Liu, Nanoscale, 2012, 4, 613-620.

23 P. Scherrer, Göttinger Nachrichten Math. Phys., 1918, 2, 98-100.

24 V. Swamy, A. Kuznetsov, L. S. Dubrovinsky, R. A. Caruso, D. G. Shchukin and B. C. Muddle, Phys. Rev. B, 2005, 71, 184302.

25 S. Osswald, V. N. Mochalin, M. Havel, G. Yushin and Y. Gogotsi, Phys. Rev. B, 2009, 80, 075419.

26 A. C. Ferrari and J. Robertson, Phys. Rev. B, 2000, 61, 14095-14107.

27 G. N. Yushin, E. N. Hoffman, A. Nikitin, H. Ye, M. W. Barsoum and Y. Gogotsi, Carbon, 2005, 43, 2075-2082.

28 Y. G. Gogotsi and F. Porz, Corros. Sci., 1992, 33, 627-640.

29 S. Brunauer, P. H. Emmett and E. Teller, J. Am. Chem. Soc., 1938, 60, 309-319.

30 V. Subramanian, A. Karki, K. I. Gnanasekar, F. P. Eddy and B. Rambabu, J. Power Sources, 2006, 159, 186-192.

31 S. Ding, J. S. Chen, D. Luan, F. Y. C. Boey, S. Madhavi and X. W. Lou, Chem. Commun., 2011, 47, 5780-5782.

32 D. Cai, P. Lian, X. Zhu, S. Liang, W. Yang and H. Wang, Electrochim. Acta, 2012, 74, 65-72.

33 J.-Y. Shin, D. Samuelis and J. Maier, Adv. Funct. Mater., 2011, 21, 3464-3472.

34 R. Ghosh, M. K. Brennaman, T. Uher, M.-R. Ok, E. T. Samulski, L. E. McNeil, T. J. Meyer and R. Lopez, ACS Appl. Mater. Interfaces, 2011, 3, 3929-3935.

35 N. S. Jacobson, Y. G. Gogotsi and M. Yoshimura, J. Mater. Chem., 1995, 5, 595-601.

36 X. Wang, G. Li, Z. Chen, V. Augustyn, X. Ma, G. Wang, B. Dunn and Y. Lu, Adv. Energy Mater., 2011, 1, 1089-1093.

37 G. Li, X. Wang and X. Ma, J. Energy Chem., 2013, 22, 357-362. 